\title{
Self-leadership and interpersonal competences of future aspiring professionals in the Arab Mid- dle East: Reference to FIRO-B
}

\author{
Deepika Gaur ${ }^{a^{*}}$
}

${ }^{a}$ American University in the Emirates, United Arab Emirates

\begin{tabular}{l}
\hline C H R O N I C L E \\
\hline Article history: \\
Received: June 11, 2019 \\
Received in revised format: June \\
292019 \\
Accepted: July 3, 2019 \\
Available online: \\
July 3, 2019 \\
\hline Keywords: \\
Interpersonal needs \\
FIRO-B, interpersonal training \\
Team work \\
Soft skills \\
Self-leadership \\
Aspiring professionals \\
\hline
\end{tabular}

\section{A B S T R A C T}

The interpersonal competences and good relationship among employees are directly linked to the team effectiveness and indirectly to the higher productivity at the workplace. Therefore, the aim of this study is to identify interpersonal needs of Arab business students by using Fundamental Interpersonal Relations Orientation-Behaviour instrument (FIRO-B). The study is based on the survey of 192 business students in the UAE. The results have also revealed that the gender and academic level of participants had an influence on their interpersonal needs. The study has shown that it is essential to have different approaches towards students on the bases of their interpersonal needs and, by doing so, to try to enhance their interpersonal and communication skills. Moreover, the gender and academic level of students should be considered when organizing training in the improvement of students' soft skills.

Self-leadership

Aspining professionals

C 2019 by the authors; licensee Growing Science, Canada

\section{Introduction}

Commending the value of interpersonal relationships in the workplace has widely become accepted. In the world of the corporate networks, individuals are encouraged to work in teams, and how well they maintain their interpersonal relations has become the indication of their overall success. Moreover, the previous research has shown that good interpersonal relations in the workplace lead to the increase of organizations' innovation performance (Koster \& Bloem, 2018). Therefore, assessment of interpersonal competences has become one of the most significant factors in managing proper functioning of organizations. Perhaps not only from point of view of an organization but also from the anthropological point of view, people have a basic instinct to socialize and interact, and they have a need to share their social self with others, in various surroundings such as work, family, or society in general. The difference appears to be in socializing styles, and, thus, some interactions may be compatible and some of them can create a pathway to conflicts. Healthy and non-healthy surroundings in the workplace based on interpersonal relationships, can affect the perception of the workplace itself.

\footnotetext{
* Corresponding author. Tel.: +60146856048

E-mail address: gaurdeepika4@gmail.com (D. Gaur) 
The assessment of interpersonal needs and psychological impact of these interactions are substantial for the analysis of the relational consequences. Moreover, the interpersonal relationships at the workplace are made up of complex connections which are comprised of emotional systems, expectations, elements of fear and optimism, as well as the urge of reaching a goal. In this ladder of success that leads towards the goal, individuals remain sensitive about the network they work in, within the organization. The assessment of the complex interpersonal relationships can be done through Schutz's (1958) FIRO-B (Fundamental Interpersonal Relations Orientation-Behaviour) instrument. The assessment can be used not only to find out the employees' interpersonal needs, but it can also be used in training of the employees and making them aware of each other's needs. Finally, the foundation of every human life is to understand their own interpersonal relationship type (Reis et al., 2000).

One of the greatest contributions of FIRO-B instrument is in evaluating interpersonal compatibility, i.e. analysing if one person's scores match another person's scores (Furnham, 2008). It is an extremely useful instrument for understanding the consistency of individuals' behaviour within the team and analysing team compatibility. As Schutz (1994) pointed out, the team compatibility is assessed by measuring "person to person compatibility" and "person to team compatibility". Therefore, FIRO-B instrument can give an insight into creating a smooth process of interactions among the team. From the point of view of leaders and managers, since they play an important part in a group building and team developing, the tool gives the managers an understanding of the nature of the team which can enhance the group functioning if used in a proper way. When it comes to the leader-follower relationship, in order to be compatible, a leader should understand the requirements of a team in terms of their needs. There should even be a balance between the execution of the leader's needs and the team's understanding of the leader's needs, in order for the team to function effectively. Hence, this instrument can be helpful in creating the awareness of social interaction index of an individual and resolving conflicts arising due to the behavioural incompatibility.

None of the studies known to the authors has been evaluating the interpersonal needs of business students in Arab countries, particularly the UAE, using FIRO-B instrument. Therefore, the goal of this study is to analyse the UAE business students' interpersonal relationship orientation using Fundamental Interpersonal Relations Orientation-Behaviour (FIRO-B) inventory developed by Schutz (1992). Moreover, the study tries to provide guidance for developing the training for enhancement of business students' interpersonal competences.

The examination of the interpersonal relationship orientation is particularly important in the Arab context, especially the UAE context since it is characterized by the extremely diversified workforce. Diversity and multiculturalism are crucial characteristics of the workforce in the UAE (Yousef, 2000). Moreover, one of the crucial aspects of Arab business interactions is nurturing personal relationships and being able to aid business relationships (Howe-Walsh et al., 2015). Thus, it is essential for the UAE students to get prepared for functioning and working in multicultural teams and perhaps one day for leading them. Since the interpersonal relationship is very important at the workplace, the duty of business colleges, especially in the diversified environment such as the UAE, is to develop interpersonal excellence among their students. By identifying their interpersonal needs, business students will not only understand their interpersonal orientation, but they will also be able to comprehend differences in human behaviour in interpersonal relationships. As a result, they will have a better rapport with their colleagues and team members in the future which is essential for the productive functioning of teams and organizations, particularly it is crucial for the diversified organizational environment.

In the next section, we explain the concept of the Fundamental Interpersonal Relationship OrientationsBehaviour (FIRO-B). Then, we present the research methodology and results. At the end, we discusse the limitations of the findings, suggest directions for future research and present a summary of the study. 


\subsection{Understanding FIRO-B}

The FIRO-B assessment is a tool for assessing interpersonal needs, rather than capability or career scope of an individual. Fundamental Interpersonal Relationship Orientations-Behaviour tool, published in 1958 by William Schutz, has been used in organizations for various purposes. The purpose of FIRO-B assessment is to describe the individual's behaviour towards others and vice versa, i.e., how do others behave towards individuals (Cunningham \& Taylor, 2009). An interpersonal relationship is administered in a situation where two individuals interact and consider one another's requirements to reach a decision and purpose (Schutz, 1958). An interpersonal need is fulfilled by satisfactory relation with others (Schutz, 1958, p. 58). FIRO-B tool helps to evaluate behaviour derived from the interpersonal need for inclusion, control and affection in an attempt to enhance interpersonal relations (Hammer \& Schnell, 2000; Siegel et al., 2001; Thompson \& Schutz, 2000; etc.). The instrument focuses on understanding these three needs from the aspect of expressed and wanted behaviour.

The need for inclusion depicts the aspect of social interaction, as well as the aspect of association with others. The high score in this need indicates the priority of an individual to include someone in the group or get included in someone's group. These individuals often possess a desire to belong and to be accepted by others (Siegel \& Miller, 2009). The need to get included and associated with others is called expressed inclusion and a need to be accepted and included by others is called wanted inclusion. According to Furnham (2008), both expressed and wanted inclusion are positively connected to extraversion.

The need for control in FIRO-B relates to the need for power, i.e. keeping the right balance of influence and power in interaction with others (Siegel \& Smith, 2001). The individuals with more expressed control tend to have the need for exerting power and influence and even to take responsibility in order to execute things under their control. On the other hand, the wanted inclusion is the need for letting others to have power and influence. Moreover, it is the need to be under the guidance and responsibility of others (Siegel \& Miller, 2009). Furnham (2008) revealed that extraversion is positively correlated only with the individuals with expressed control notion.

The aspect of affection refers to the need for closeness, love and intimacy. The expressed affection is a need to have intimacy and close friendship with others. On the other hand, individuals with a higher level of the wanted affection expect others to show love and affection towards them. The need for affection shouldn't be confused with romantic relationship feelings, but it is the need to feel close and comfortable in interpersonal relationships with others (Ditchburn \& Brook, 2015). The need for affection is positively correlated with both extraversion and agreeableness (Furnham, 2008).

Another variable which could be added to the dimensions of FIRO-B showing expressed and wanted need is the warmth variable (Wiedemann et al., 1979). The warmth variable is the addition of inclusion and affection and it refers to having warm and comfortable relations among pairs or groups. Fisher et al. (1995) supported the addition of warmth variable emerging from the combination of inclusion and affection need through the study conducted on the participation and management of software creation teams. This is the aspect which is studied along with the three previously mentioned needs of FIRO-B.

Most of the research dealing with FIRO- B have been analysing the interpersonal needs of employees (Cerny et al., 2008; Ditchburn \& Brook, 2015; Fisher et al., 1995; Fleenor \& Van Velsor, 1993; Furnham, 2007; Furnham, 2008; Jenster, 2009; Jenster \& Steiler, 2011; Krause et al., 2008; Macrosson \& Semple, 2001; Mahoney \& Stasson, 2005; Siegel et al., 2001; Siegel \& Schutz, 2011; Siegel \& Smith, 2003). Few authors have analysed FIRO-B on students' population (Hill, 1974; Hur et al., 2017; McRae \& Young, 1990; Umashankar \& Charitra, 2016; Wheeler, 2001).

Several of the previous studies have emphasized the interpersonal needs of employees. Fisher et al. (1995) evaluated group affiliation and team compatibility of software product teams. The importance of FIRO-B in assessing interpersonal need was also highlighted in the study on auditors while analysing the social interaction index (SII) for overall interpersonal orientation (Siegel et al., 2001). The same study also concluded gender differences in interpersonal need assessment wherein females scored higher for interpersonal needs in comparison to male counterparts (Siegel et al., 2001). Siegel and Schutz (2011) 
conducted the first exploratory study on the social interaction preferences of internal auditors. The study discovered a significant difference in the Social Interaction Index between internal and external auditors, but no differences in FIRO-B dimensions could be observed. Fleenor and Van Velsor (1993) and Krause et al. (2008) validated the FIRO-B instrument by comparing the results of FIRO-B self-assessment and the results of Benchmarks 360-degree feedback tool rated by supervisors, peers, customers, etc. The findings of both studies discovered similar relationships between these two tools.

Out of few studies conducted on student population, as it is known to us, only three of them have analysed business students. McRae and Young (1990) analysed Canadian students and discovered that there is no significant difference between male and female regarding FIRO-B. Umashankar and Charitra (2016) compared interpersonal skills of business students and business professionals and discovered that the score of students differed significantly from working professionals. Thus, they concluded that young professionals who are not exposed to the professional ambiance are required to be given the training to be able to have a healthy relationship in the future work environment. Hill (1974) discovered that there was a significant difference between MBA students' interpersonal needs and their preferences for different business specializations. Finally, Hur et al. (2017) analysed the interpersonal orientation of medical students with the purpose of improving the mentoring and coaching of them. As we have already mentioned none of the FIRO-B studies has been conducted in the Arab business context.

\section{Research methodology}

\subsection{Research questions}

In this research we have tested the following research questions:

1. What are business students' interpersonal needs?

2. Are there statistically significant differences in business students' interpersonal relationship behaviour across the category of gender?

3. Are there statistically significant differences in business students' interpersonal relationship behaviour across the category of academic level?

\subsection{Sample}

We conducted the research at the College of Business and Administration in the UAE during the Spring semester 2018. The number of students that completed the questionnaire was 206, however, we had to exclude 14 questionnaires because of incomplete data. Therefore, the total number of valid questionnaires was 192.

The college had both undergraduate and graduate studies. All the participants were Arabs. 53.6 of them were males and $42.8 \%$ females and 56.3 were undergraduate students (BBA) while $43.8 \%$ were graduate students (MBA).

\subsection{Instrument}

Shutz's (1992) Fundamental Interpersonal Relationship Orientation-Behaviour (FIRO-B) instrument was used to measure the personal interaction of students. The questionnaire consists of 54 items. It has two categories of interpersonal needs (inclusion, control and affection) and behaviour (expressed and wanted). Combining these two categories we get six individual needs: expressed inclusion, expressed control, expressed affection, wanted inclusion, wanted control and wanted affection. Each of these needs has the maximum score of 9 and the maximum total score is 54 . The total score represents the social interaction index (SII) which indicates the overall interpersonal need. We included in our analyses the FIRO-B attribute warmth which is calculated by adding inclusion and affection scores together (Fisher et al., 1995; Wiedemann, 1979). Fisher et al. (1995) in their study discovered that the warmth aspect had implications for the management of teams. Since managers very often must work in a team, we decided to consider this aspect in our research. 
We estimated the reliability of the instrument by using Chronbach's alpha. The alpha coefficient of FIBRO-B scale ranged from 0.762 to 0.823 which indicates that the instrument is reliable at an acceptable level (Nunnally \& Bernstein, 1994). The coefficient for each need was as follows: expressed inclusion (0.787), wanted inclusion (0.762), expressed control (0.823), wanted control (0.792), expressed affection (0.807) and wanted affection (0.790).

\section{Results}

The authors analysed the results with descriptive statistics and the independent samples t-test. The independent samples t-test was used to analyse the differences between genders and academic levels. The test was two-tailed, and we considered the $p$-value of $p<0.05$ as significant.

The social interaction index (SII) mean score for 192 students at the College of Business and Administration is 23.59 which tell us that SII of business students is in Medium-low level ${ }^{1}$. McRae and Young (1990) reported similar SII mean score (23.79) when they analysed Canadian undergraduate business students. Also, the similar SII mean score (23) was identified with Indian finance students (Umashankar $\&$ Charitra, 2016). However, the SII mean score of our respondents is higher than the SII mean score for accounting students (22.3) and lower than the score of marketing (31), manufacturing (31.7) and personnel management students (31.9) (Hill, 1974). Furthermore, it is also lower than the score of Korean medical students (24.57) (Hur et al., 2017). The UAE business students show the highest score for warmth needs (16.31), followed by inclusion (8.96), affection (7.34) and control needs (7.29). These results also indicate that students' interpersonal needs are at the medium level ${ }^{2}$. Contrary to our results, medical students showed the highest score for control needs (8.63), then for affection (8.14) and at the last place for inclusion (7.81) (Hur et al., 2017).

Students from our sample scored 9.01, 5.27, 3.74 and 3.52 for expressed warmth, inclusion, affection and control respectively. The mean score for expressed behaviour level is 12.53 which can also be classified as being at the medium level ${ }^{3}$. The mean score for expressed behaviour of our respondents is higher than expressed behaviour for Indian finance students (8.45) (Umashankar \& Charitra, 2016) and Korean medical students (11.8) (Hur et al., 2017).

For wanted warmth, control, inclusion and affection students scored 7.29, 3.77, 3.69 and 3.60 respectively. The average score for wanted behaviour is 11.06 which is at the medium level, but lower than the wanted behaviour average score of Indian finance students (11.3) (Umashankar \& Charitra, 2016) and Korean medical students (12.69) (Hur et al., 2017).

\subsection{Gender difference}

The analysis of differences between male and female scores identified statistically significant differences in several areas (Table 1). Females showed higher wanted warmth needs than males $(\mathrm{p}=0.012)$, while males showed higher expressed control than women $(\mathrm{p}=0.006)$. As far as the needs category is concerned, the difference is identified for control needs, i.e. men have the higher need for control than women $(\mathrm{p}=0.009)$ and warmth needs, i.e. women show higher need for warmth than men $(\mathrm{p}=0.028)$. Moreover, we discovered the statistically significant difference in the behaviour category, namely the wanted mean is higher for male than for female $(\mathrm{p}=0.23)$. Our results are in compliance with other studies that have identified that males have the greater need for control and females for affection and warmth (McRae \& Young, 1990; Hur et al., 2017; Siegel et al., 2001). By analysing previous literature on the FIRO-B, it is clear that only McRae and Young (1990) and Siegel (2001) have revealed the significant gender difference in SII scores. Both studies discovered that females' SII is higher than males, i.e. that women have higher interpersonal needs than men.

\footnotetext{
${ }^{1}$ SII score range: 0-15- low level; 16-26-Medium-low level; 27-38 - medium-high level; 39-54- high level

${ }^{2}$ Needs score range: 0-5 - low level; 6-12-medium level; 13-18-high level

${ }^{3}$ Behaviors score range: 0-7 - low level, 8-19-medium level, 20-27 - high level
} 
Table 1

The analysis of differences between male and female scores

\begin{tabular}{|c|c|c|c|c|c|c|c|c|c|}
\hline MF & & Mean & Std. Deviation & Std. Error Mean & MF & & Mean & Std. Deviation & Std. Error Mean \\
\hline \multirow{2}{*}{ Expressed Inclusion } & $\mathrm{M}$ & 5,44 & 1,964 & , 193 & \multirow{2}{*}{ SII } & $\mathrm{M}$ & 24,10 & 9,562 & 942 \\
\hline & $\mathrm{F}$ & 5,08 & 1,902 & .202 & & $\mathrm{~F}$ & 23,61 & 8,864 & 940 \\
\hline \multirow{2}{*}{ Wanted Inclusion } & $\mathrm{M}$ & 3,40 & 2,081 & 205 & \multirow{2}{*}{ Inclusion } & $\mathrm{M}$ & 8,84 & 3,699 & 392 \\
\hline & $\mathrm{F}$ & 4,34 & 2,563 & .272 & & $\mathrm{~F}$ & 9.42 & 4,176 & 412 \\
\hline \multirow{2}{*}{ Expressed Control } & $M$ & $4,22 *$ & 2,967 & 292 & \multirow{2}{*}{ Control } & $\mathrm{M}$ & $8,10^{*}$ & 4,231 & 448 \\
\hline & $\mathrm{F}$ & $3,08 *$ & 2,752 & .292 & & $\mathrm{~F}$ & $6,72 *$ & 3,518 & 347 \\
\hline \multirow{2}{*}{ Wanted Control } & $\mathrm{M}$ & 3,87 & 2,412 & 238 & \multirow{2}{*}{ Affection } & $\mathrm{M}$ & 7,16 & 3,789 & 402 \\
\hline & $\mathrm{F}$ & 3,64 & 2,577 & .273 & & $\mathrm{~F}$ & 7,47 & 4,338 & 427 \\
\hline \multirow{2}{*}{ Expressed Affection } & $\mathrm{M}$ & 3,84 & 2,283 &, 225 & \multirow{2}{*}{ Warmth } & $M$ & 16,00 & 6,491 &, 688 \\
\hline & $\mathrm{F}$ & 3.62 & 2.182 & .231 & & $\mathrm{~F}$ & 16.89 & 7.579 & .747 \\
\hline \multirow{2}{*}{ Wanted Affection } & $\mathrm{M}$ & 3,31 & 2,396 & 254 & \multirow{2}{*}{ Expressed } & $\mathrm{M}$ & 13,50 & 4,656 &, 459 \\
\hline & $\mathrm{F}$ & 3,85 & 2,510 & 247 & & $\mathrm{~F}$ & 11,78 & 4,444 & 471 \\
\hline \multirow{2}{*}{ Expressed Warmth } & $\mathrm{M}$ & 9,28 & 3,620 & 357 & \multirow{2}{*}{ Wanted } & $\mathrm{M}$ & $10,59^{*}$ & 5,577 & 591 \\
\hline & $\mathrm{F}$ & 8,70 & 3,266 & (346 & & $\mathrm{F}$ & $11,83^{*}$ & 5,983 & .589 \\
\hline \multirow{2}{*}{ Wanted Warmth } & $\mathrm{M}$ & $6,72 *$ & 4,428 & ,469 & & & & & \\
\hline & $\mathrm{F}$ & $8,19^{*}$ & 4,721 & 465 & & & & & \\
\hline
\end{tabular}

\subsection{Academic level differences}

As explained the independent samples t-test was used to analyse mean differences between undergraduate (BBA) and graduate (MBA) business students across the areas of interpersonal needs (Table 2).

Table 2

The analysis of the mean difference

\begin{tabular}{|c|c|c|c|c|c|c|c|c|c|}
\hline Qualification & & Mean & Std. Deviation & $\begin{array}{l}\text { Std. } \\
\text { Error }\end{array}$ & Qualification & & Mean & $\begin{array}{l}\text { Std. } \\
\text { Deviation }\end{array}$ & Std. Error Mean \\
\hline \multirow{2}{*}{ Expressed Inclusion } & $\mathrm{BBA}$ & 5,07 & 1,863 &, 179 & \multirow{2}{*}{ SII } & $\mathrm{BBA}$ & 24,00 & 10,725 & 1,170 \\
\hline & MBA & 5,52 & 2,015 &, 220 & & MBA & 23,46 & 7,950 &, 765 \\
\hline \multirow{2}{*}{ Wanted Inclusion } & BBA & $4,50^{*}$ & 1,929 &, 211 & \multirow{2}{*}{ Inclusion } & BBA & 9,57 & 4,543 &, 496 \\
\hline & MBA & $3,15^{*}$ & 2,283 &, 220 & & MBA & 8,67 & 3,539 &, 341 \\
\hline \multirow{2}{*}{ Expressed Control } & BBA & 3,62 & 2,027 & ,195 & \multirow{2}{*}{ Control } & BBA & 7,51 & 3,389 &, 326 \\
\hline & MBA & 3,39 & 2,639 & ,288 & & MBA & 7,00 & 4,388 & ,479 \\
\hline \multirow{2}{*}{ Wanted Control } & BBA & 3,89 & 2,489 & ,239 & \multirow{2}{*}{ Affection } & BBA & 6,92 & 3,975 & ,382 \\
\hline & MBA & 3,61 & 2,489 & ,272 & & MBA & 7,79 & 4,064 & ,443 \\
\hline \multirow{2}{*}{ Expressed Affection } & BBA & 3,50 & 2,866 &, 276 & \multirow{2}{*}{ Warmth } & BBA & 16,49 & 8,102 &, 884 \\
\hline & MBA & 3,94 & 2,983 &, 326 & & MBA & 16,46 & 6,135 &, 590 \\
\hline \multirow{2}{*}{ Wanted Affection } & BBA & 3,42 & 2,349 &, 226 & \multirow{2}{*}{ Expressed } & BBA & 12,19 & 4,196 & ,404 \\
\hline & MBA & 3,85 & 2,604 &, 284 & & MBA & 12,86 & 4,862 &, 531 \\
\hline \multirow{2}{*}{ Expressed Warmth } & $\mathrm{BBA}$ & $8,57^{*}$ & 3,372 & ,324 & \multirow{2}{*}{ Wanted } & $\mathrm{BBA}$ & $11,81^{*}$ & 6,566 & ,716 \\
\hline & MBA & $9,46^{*}$ & 3,333 &, 364 & & MBA & $10,60 *$ & 5,268 &, 507 \\
\hline \multirow{2}{*}{ Wanted Warmth } & BBA & 7,92 & 5,179 &, 565 & & & & & \\
\hline & MBA & 6,99 & 4,183 &, 403 & & & & & \\
\hline
\end{tabular}

The BBA students showed higher wanted inclusion $(\mathrm{p}=0.000)$ than the MBA. On the other hand, the MBA students showed higher expressed warmth $(p=0.000)$ need. Examining expressed and wanted behaviour categories, we discovered that wanted mean is significantly higher for BBA students than for MBA ( $p=0.017)$. Finally, the significant differences in the needs category were not discovered.

\section{Discussion}

This research has determined that there are statistically significant differences in business students' interpersonal needs across gender and academic level category. The business students show not only moderate needs for inclusion, affection, control and warmth, but also moderate scores for expressed and wanted behaviour. As a consequence of moderate scores in all categories, the score of SII was also moderate. The differences between male and female are identified for expressed control and wanted affection dimensions. Males want more expressed control while females show higher wanted warmth needs. Moreover, male students expressed the higher need for control than female. These results are not surprising if we consider that the Arab culture is still traditional where men have a more dominant role in families. Also, according to Hofstede's classification of national cultures, the UAE belongs to masculinity cultural dimension where social genders are clearly divided, i.e. men are supposed to be tough, assertive and focused on success and women should be modest, affectionate, caring, supportive and 
oriented towards family (Hofstede, 2001). Thus, it is expected that male students want more control and female more warmth. We can conclude that findings from our study support gender stereotypes which identifies women as being considering, carrying and men as being dominant and controlling. The undergraduate students show higher wanted inclusion than postgraduate students which is the expected result since undergraduate students, especially a first-year and second-year students have higher need to be included in school activities and to adjust to the school system. Graduate students are adjusted to the school and they do not have those needs anymore. On the other hand, they show higher expressed warmth which indicates that they are more oriented towards teamwork and adoption of common goals. These results can be due to the fact that postgraduate students are more mature and more aware of the benefits of being part of a good team.

The limitation of our study regards the number of respondents in our research. It is difficult to generalize these results since the research was conducted in only one college in the UAE. In the future research, more universities and countries could be included, and even cross-cultural comparison could be conducted. Moreover, it would be interesting to analyse the difference between students' interpersonal needs and an academic year they have enrolled. We believe that there would be differences in interpersonal needs of first-year undergraduate students and fourth-year. Finally, we can expand future studies by comparing the FIRO-B instrument with other interpersonal relationship instruments or even trying to find the relationship between the Big Five personality test or MBTI and FIRO-B

\section{Conclusion}

The purpose of this study was to identify interpersonal needs of business students and whether different approaches were required for students with different interpersonal needs. Up to now, only few studies have analysed business students' interpersonal needs. However, none of these studies analysed the UAE business students' needs and the differences between interpersonal needs of undergraduate and graduate business students. Furthermore, none of the studies about students' interpersonal needs included the warmth category in their research. It is essential that interpersonal needs (inclusion, control, affection and warmth) of an individual match with the work environment, otherwise we are going to have unhappy employees and that will hamper their tasks (Thompson, 2001). Therefore, we believe that it is very important to identify interpersonal needs of business students by using FIRO-B. Once they finish colleges these students will need to work in teams, to acquire leadership position and to have a good rapport with both external and internal stakeholders. The students will be more productive at their work and more able to handle workplace conflicts if they are trained in interpersonal skills. Our research has shown that it is essential to have different approaches towards students on the bases of their interpersonal needs and, by doing so, to try to enhance their interpersonal and communication skills. Therefore, when organizing training in the improvement of students' soft skills and developing educational programs, we should consider the gender and academic level of students.

\section{References}

Cerny, L.J., Smith, D.S., Ritschard, H., \& Dodd, C.H. (2008). Development of the CernySmith Adjustment Index (CSAI) as an Integrative Cross-cultural Adjustment Assessment. Orange, CA: CernySmith Assessments.

Cunningham, D., \& Taylor, N. (2009). Fundamental Interpersonal Relations Orientation Behaviour (FIRO-B® ASSESSMENT). Technical Report. Johannesburg: Jopie van Rooyen and Partners (Pty) Ltd.

Ditchburn, G., \& Brook, E. R. (2015). Cross-cultural adjustment and fundamental interpersonal relations orientation behaviour (FIRO-B). Journal of Global Mobility, 3(4), 336-349.

Fisher, S. G., Macrosson, W. D. K., \& Walker, C. A. (1995). FIRO-B: The power of love and the love of power. Psychological Reports, 76(1), 195-206.

Fleenor, J. W., \& Van Velsor, E. (1993). The relationship between Benchmarks ${ }^{\circledR}$ and personality measures used in the Leadership Development Program. Greensboro, NC: Center for Creative Leadership.

Furnham, A. (2007). Personality and Intelligence at Work. R London: Routledge.

Furnham, A. (2008). Psychometric Correlates of FIRO-B Scores: Locating the FIRO-B scores in personality factor space. International Journal of Selection and Assessment, 16(1), 30-45.

Hammer, A. L., \& Schnell, E. R. (2000). FIRO-B: Technical Guide, Consulting Psychologists. 
Hill, R. E. (1974). Interpersonal needs and functional area of management. Journal of Vocational Behavior, 4(1), $15-24$.

Hofstede, G. (2001). Culture's recent consequences: Using dimension scores in theory and research. International Journal of Cross-Cultural Management, 1(1), 11-17.

Howe-Walsh, L. J., Turnbull, S. L., \& Boulanouar, A. (2015). International human resource management: implications for multinational corporations operating in the Arab Middle East. International Journal of Human Resources Development and Management, 15(2/3/4), 258-274.

Hur, Y., Cho, A. R., Huh, S., \& Kim, S. (2017). How do medical students differ in their interpersonal needs?. BMC Medical Education, 17(1), 42-47.

Jenster, N.P. (2009). Leadership impact on motivation, cohesiveness and effectiveness in virtual teams: a FIRO perspective. doctoral dissertation, Ecole de management supervisors: Dr Dominique Steiler Dr Wu Min. Shanghai, China: Tongji University

Jenster, N.P., \& Steiler, D. (2011). Turning up the volume in inter-personal leadership: motivating and building cohesive global virtual teams during times of economic crisis. Advances in Global Leadership, 6, 267-297

Koster, F., \& Bloem, D. (2018). "Have a little faith" A vignette study of inter-organizational cooperation and innovation performance. International Journal of Business Science and Applied Management, 13(1), 25-41.

Krause, N.A., Anderson, M. G., \& Thompson, R. C. (2008). Validation of the FIRO-B ${ }^{\circledR}$ Instrument with Benchmarks ${ }^{\circledR}$ Performance Dimensions. CPP, Inc

Macrosson, W. D. K., \& Semple, J. H. (2001). FIRO-B, Machiavellianism, and teams. Psychological reports, 88(3_suppl), 1187-1193.

Mahoney, J. M., \& Stasson, M. F. (2005). Interpersonal and Personality Dimensions of Behavior: FIRO-B and the Big Five. North American Journal of Psychology, 7(2).

McRae, I., \& Young, J. (1990). Field independence and the FIBRO-B. Perceptual and Motor Skills, 70, 493-4.

Nunnally, J.C., \& Bernstein, I.H. (1994). Psychometric Theory ( $3^{\text {rd }}$ ed.). New York, NY: McGraw-Hill.

Reis, H.T., Collins, W.A., \& Berscheid, E. (2000). The relationship context of human behaviour and development. Psychol Bull, 126(6), 844-72.

Siegel, P. H., \& Miller, J. R. (2009). An international comparison of social interaction attributes of internal auditors: an analysis using the Firo-B. The Leadership and Organizational Development Journal, 31(1), 114-126.

Siegel, P. H., Smith, J. W., \& Mosca, J. B. (2001). Mentoring relationships and interpersonal orientation. The Leadership and Organizational Development Journal, 22(3), 114-126.

Siegel, P. H., \& Schultz, T. (2011). Social Skills Preferences Among Internal Auditors-An Explanatory Study Using The FIRO-B. Journal of Applied Business Research, 27(3), 43.

Schutz, W. C. (1958). FIRO: A Three Dimensional Theory of Interpersonal Behavior. New York, NY: Holt, Rinehart and Winston.

Schutz, W. C. (1992). Beyond FIRO-B: Three new theory derived measures, element B: behavior, element F: feelings, element S: self. Psychological Reports, 70, June, 915-937.

Schutz, W. (1994). The Human Element: Productivity, Self-Esteem and the Bottom Line. San Francisco, CA: Jossey-Bass.

Umashankar, K., \& Charitra, H. G. (2016). Enhancing Interpersonal Competency through Soft-Skills Training with Reference to FIRO-B. Adarsh Journal of Management Research, 9(1), 21-28.

Wiedemann, C., Waxenberg, S. E., \& Mone, L. C. (1979). Factor Analysis of FIRO-B and FIRO-F. Small Group Behavior, 10(1), 49-61.

Wheeler, P. (2001). The Myers-Briggs Type Indicator and applications to accounting education and research. Issues in Accounting Education, 16(1), 125-150.

Thompson, H., \& Schutz, W. (2000). FIRO element B organizational interpretive report. Watkinsville, GA: High Performing Systems.

Thompson, H. L. (2001). Introduction to FIRO Element B in Organizations. Wormhole Pub.

Yousef, D. A. (2000). The Islamic work ethic as a mediator of the relationship between of control, role conflict and role ambiguity: A study in an Islamic country setting. Journal of Managerial Psychology, 15(4), 283-298.

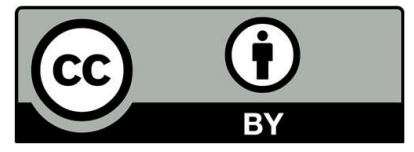

(C) 2019 by the authors; licensee Growing Science, Canada. This is an open access article distributed under the terms and conditions of the Creative Commons Attribution (CCBY) license (http://creativecommons.org/licenses/by/4.0/). 